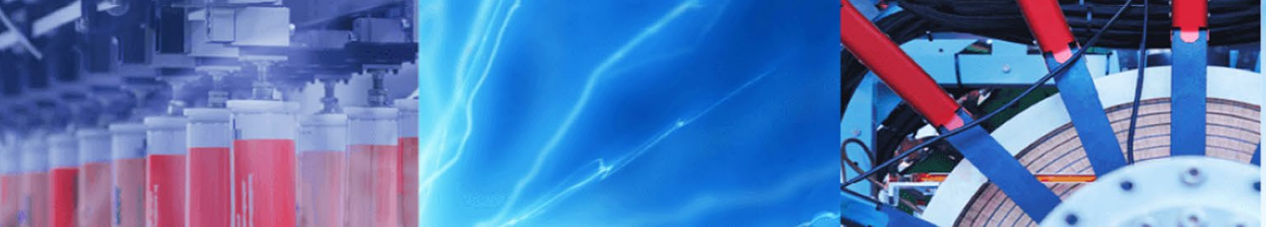

Research Article

\title{
Electrospun cellulose acetate and poly(vinyl chloride) nanofiber mats containing silver nanoparticles for antifungi packaging
}

\author{
Bethwel K. Tarus ${ }^{1}$ (D) Josphat I. Mwasiagi ${ }^{1} \cdot$ Nermin Fadel $^{2} \cdot$ Affaf Al-Oufy $^{2} \cdot$ Magdi Elmessiry $^{2}$
}

(c) Springer Nature Switzerland AG 2019

\begin{abstract}
Nanofiber mats of poly(vinyl chloride) (PVC) and cellulose acetate (CA) encapsulated with silver (Ag) nanoparticles were fabricated via electrospinning for potential use as antimicrobial food packaging materials. $16 \mathrm{wt} \%$ PVC was prepared in 1:1 w/w tetrahydrofuran $-N, N$-dimethylformamide while $16 \mathrm{wt} \%$ CA was prepared in $3: 2(\mathrm{w} / \mathrm{w})$ Acetone- $N, N$-dimethylformamide. Scanning electron microscopy analysis showed that thinner fibers could be electrospun from cellulose acetate as compared to poly(vinyl chloride) at the same solution concentrations with fiber diameters ranging from 70 to $130 \mathrm{~nm}$ for cellulose acetate and 180-340 nm for poly(vinyl chloride). Nanofiber diameter reduced with addition and increase of silver nanoparticles from 0 to $1 \mathrm{wt} \%$. Due to the smaller cellulose acetate nanofiber diameter, its mats had lower air permeability rates. Tensile strength tests indicated that the nanofiber mats had marginal to good tensile strength values relative to film based packaging materials. Antimicrobial examination of the nanofiber mats against yeast and mould indicated that there was inhibited growth of the microorganisms on mats containing silver nanoparticles.
\end{abstract}

Keywords Electrospun nanofibers · Antifungi food packaging $\cdot$ Cellulose acetate $\cdot$ Poly(vinyl chloride) $\cdot$ Silver nanoparticles

\section{Introduction}

Packaging materials are an important component of product preservation especially food products whose quality should be maintained in its original state until consumption. Important determinants of product quality preservation are the physical and barrier properties of the package and especially to fresh produce which are subject to rapid microbial degradation when exposed. Generally, the main objectives of a package material include maintaining quality during transportation and storage and extending the products shelf life. Forms of packaging in the conventional sense have always been intended for protection, communication, convenience and containment [1]. In modern production, packaging materials are continually being improved to offer wider functionalities due to demand, advancement in technology and focussed research. For food products, packaging has evolved to become a complex activity where the package is required to interact with its content and react accordingly in order to prevent any alteration in the product's quality [2-6]. Other than maintaining quality, the nature of the packaging materials today is of essence in terms of weight, source reduction, energy optimization, environmental impact and food safety. Since the introduction of nanotechnology, many opportunities for the creation of low cost, lightweight and better products with improved functionalities have been presented. Significantly, material properties can be manipulated to a greater degree than before, for example, active agents in the nanoscale can be encapsulated into the packaging's matrix for functional effect against microbes. Most state of the art packaging technologies and materials, however, are energy intensive and require costly equipment, hence limiting their use for

$\triangle$ Bethwel K. Tarus, bethweltarus@gmail.com| ${ }^{1}$ School of Engineering, Moi University, P.O. Box 3900, Eldoret 30100, Kenya. ${ }^{2}$ Textile Engineering Department, Faculty of Engineering, Alexandria University, Alexandria, Egypt.

SN Applied Sciences (2019) 1:245 | https://doi.org/10.1007/s42452-019-0271-4 
commercial applications [7]. Among materials that have received attention for food packaging include nanofiber mats which have high potential for innovative and smart packaging applications $[8,9]$. Nanofiber mats can easily be fabricated from both synthetic and natural polymers and offer many advantages over other materials including being lightweight and providing more accessibility for controlling and manipulating functional properties during manufacture.

Electrospinning is a simple and very popular method of fabricating nanofiber mats. This technique allows for high volume production of extremely lightweight and highly functional nanofiber mats having uniform morphology and with extensive applications [10]. It is a relatively easy and cost effective technique that requires simple tooling and setup [11]. The applications of nanofibers fabricated through this method vary widely including being used in making certain surgical textiles, tissue scaffolds, filters, sensors and catalysis reactions [12-25]. The electrospinning process involves electrically charging a polymer solution to create very fine jets that get stretched and dry as they approach a grounded target which serves as a collector [26]. The target could be stationary to collect a mat containing randomly oriented nanofibers, or in rotation so as to achieve some alignment of the nanofibers. Electrospun materials have been shown to have potential applications in food and food packaging materials making use of biopolymers, biocompatible polymers and edible polymers $[8,9,27]$. Among the major functions of packaging materials for food products nanofibrous materials can help achieve is quality maintenance and elongating the product's life usually in combination with functional agents. Electrospinning can easily be used to achieve packaging materials meeting conventional package functions with additional capabilities like antimicrobial activity. Ultrafine antimicrobial fibers have exhibited better antimicrobial activity than conventional fibers or films because of their high surface area-to-volume ratio [28]. Prospective use of electrospun nanofiber mats in food packaging has been reported on, whereby biodegradable polyurethane supplemented with virgin olive oil and zinc oxide was electrospun for the packaging of fresh or processed meat and meat based products [29]. In most food products, microbial growth and spoilage mainly occurs at the food surface with fungi being the primary culprit $[30,31]$ and more specifically the Aspergillus species which are the most abundant fungi worldwide [32]. For effective improvement of the shelf life and storage stability of packaged food, the growth of microbes on the surface should be controlled by total elimination or minimizing the growth significantly. This can effectively be achieved by introducing an antimicrobial agent on the food surface or by using a packaging system that inhibits microbial activity $[33,34]$.
Silver (Ag) nanoparticles offer quite remarkable antimicrobial properties and have received a lot of attention. Ag in nanoparticle form is quite an effective antimicrobial as it has been shown to exert high activity against both grampositive and gram-negative food borne bacteria including Escherichia coli, Enterococcus faecalis, Staphylococcus aureus, Vibrio cholerae, Pseudomonas aeruginosa, Bacillus subtilis, Salmonella enterica, Typhimurium among several others $[35,36]$. In a recent study, it was reported that the growth of fungi was considerably weakened when spores were incubated in direct contact with Ag nanoparticles or on cellulose acetate composite membranes containing the nanoparticles [37]. Cellulose pads containing Ag nanoparticles have been reported to reduce the microbial levels of exudates from beef meat stored in modified atmosphere packaging [38], and fresh cut melon stored on cellulose pads containing Ag nanoparticles exhibited reduced microbial counts with longer microbial growth lag times [39]. Danza et al. [40] incorporated silver-montmorillonite nanoparticles into an alginate-based coating and determined its antimicrobial effects using fresh cut melon. A significant shelf life increase was recorded from less than 3 days for the control samples to 11 days for the coated fruit.

Many synthetic polymers have been used in packaging materials with PVC being among the most commonly produced and used especially in plumbing, construction and packaging $[41,42]$. PVC is listed as the sixth widely used polymer of packaging plastics at $2 \%$ after low density and linear low-density polyethylene films at $30 \%$, high-density polyethylene at $26 \%$, polyethylene terephthalate at $18 \%$, polypropylene at $14 \%$ and polystyrene at $8 \%$ [43]. PVC cling films are used widely both in the fresh produce and processed food markets. PVC is quite popular because of its numerous advantages of easy workability by thermoplastic methods, wide range of flexibility possible with varying levels of plasticizers, non-flammability, dimensional stability, comparatively low cost and good resistance to weathering [41]. PVC has been electrospun successfully in Tetrahydrofuran solvent [44] and in a binary solvent system of tetrahydrofuran-dimethylformamide [45]. A majority of the films for packaging fresh produce are clear allowing for easy inspection of the contents. They are available in a wide range of thicknesses and grades and may be modified to control the environment inside the package. Generally, many fresh produce are packaged in polystyrene trays and wrapped in plastic polyethylene or PVC films. However, renewability and environmental concerns have been shifting attention of research towards environmentally friendly and biodegradable polymers. Polymers like polylactide [46], polyurethane [29], cellulose acetate [28], chitosan [47, 48], poly(vinyl alcohol) [49] 
among others have attracted a lot of interest in research with successful reports for use in antimicrobial packaging due to their biodegradability and compatibility. Of interest to this study is cellulose acetate (CA), a regenerated natural polymer from purified cellulose. Depending on the path taken during processing, CA can be used in a wide variety of applications as films or fibers. Generally, regenerated cellulosic polymers are receiving attention for use in food contact applications because of their nontoxicity, edibility and biocompatibility [37]. Successful electrospinning of CA has been achieved using a variety of solvents [50].

The objective of this study was to fabricate PVC and CA nanofiber mats through electrospinning and then evaluate their physical, mechanical and antimicrobial performance for potential application in packaging materials for fresh fruits and vegetables. Fabricated mats were tested on common fungi affecting fresh produce. Existing literature on the antifungal effects of $\mathrm{Ag}$ are few in comparison with those on antibacterial effects. Therefore, this study also aims to quantitatively and qualitatively improve on literature on antifungal effects of Ag. Solvent casting technology was used to fabricate films for comparison purposes. The solvents used for this study were selected basing on the findings of a previous study [50]. Important solvent properties that affect the electrospinning process and nanofiber properties are the dielectric constant, shear viscosity and surface tension among other properties. Properties of the solvents used in this study are given in Table 1 [51].

\section{Methods}

\subsection{Materials}

In this study, poly(vinyl chloride) (PVC), of Mw 80,000 and Cellulose acetate (CA), of Mw 30,000 were used for fabrication of the mats and cast films. Solvents used were $\mathrm{N}, \mathrm{N}$-dimethylformamide (DMF), Tetrahydrofuran (THF) and acetone. Silver nanoparticles of $<100 \mathrm{~nm}$ were used. These resources were supplied by Sigma Aldrich (US) and were used without further purification.

\subsection{Nanofiber mat and cast film fabrication}

Electrospinning PVC solutions were prepared at $16 \mathrm{wt} \%$ in 1:1 w/w THF-DMF solvent system, while CA solutions were prepared at $16 \mathrm{wt} \%$ in $3: 2 \mathrm{w} / \mathrm{w}$ acetone-DMF solvent system at room temperature. Electrospinning the polymers at this solution concentrations using the given solvents had been found to have optimal processing, physical and mechanical characteristics in a previous study [50]. Agloaded polymer solutions were prepared at $0.4,0.6,0.8$ and $1 \mathrm{wt} \%$ Ag nanoparticles relative to the polymer weight. For each polymer, the solvent mixture was added to vials containing weighed Ag nanoparticles which were then sonicated for $2 \mathrm{~h}$ before addition of the respective polymer. The solutions were stirred using a magnetic stirrer for $6 \mathrm{~h}$ to attain maximum homogeneity of the solution and $\mathrm{Ag}$ nanoparticles mixture. An electrospinning spinneret having $0.9 \mathrm{~mm}$ internal diameter and a variable high DC voltage supply were used to electrospin nanofiber mats onto a stationary aluminium foil at $20 \mathrm{kV}, 20 \mathrm{~cm}$ collection height and $4 \mathrm{~h}$ collection time. Solvent cast films were fabricated from similar solutions as those prepared for electrospinning using the technique described in previous work [50].

\subsection{Material characterization}

Morphological properties of the electrospun nanofiber mats were obtained using a JEOL-5300 scanning electron microscope at $\times 5000$ and $\times 20,000$ magnifications and an electron acceleration voltage of $20 \mathrm{kV}$ for the nanofibers. Resulting scanning electron microscopy (SEM) images were used to perform nanofiber diameter measurement using the advanced image analysis software, ImageJ. A MesdanLab tensile strength tester set with a load cell of $100 \mathrm{~N}$ and a clamp speed of $50 \mathrm{~mm} / \mathrm{min}$ was used to perform tensile strength analysis of the nanofiber mats and cast film. Air permeability tests of the electrospun nanofiber mats were performed using a Porosimeter (JDC MK1). For the tests, the time necessary for 0.25 litres of air under 10 mbar pressure to go through $38.5 \mathrm{~cm}^{2}$ of sample

Table 1 Properties of solvents used

\begin{tabular}{lllllll}
\hline Solvent type & Density $\left(\mathrm{g} / \mathrm{cm}^{3}\right)$ & Boiling point $\left({ }^{\circ} \mathrm{C}\right)$ & $\begin{array}{l}\text { Dipole moment } \\
(\text { Debye })\end{array}$ & $\begin{array}{l}\text { Dielectric } \\
\text { constant }\end{array}$ & $\begin{array}{l}\text { Shear viscosity } \\
(\mathrm{mPa})\end{array}$ & $\begin{array}{l}\text { Surface } \\
\text { tension } \\
(\mathrm{mN} / \mathrm{m})\end{array}$ \\
\hline Acetone & 0.786 & 56.3 & 2.70 & 20.7 & 0.304 & 22.7 \\
$N, N$-Dimethylformamide & 0.945 & 153.0 & 3.82 & 37.0 & 0.796 & 36.3 \\
Tetrahydrofuran & 0.8892 & $65-67$ & 1.750 & 7.52 & 0.456 \\
\hline
\end{tabular}


was measured. Air permeability was then determined in litre $/ \mathrm{m}^{2} / \mathrm{min}$ using the expression given in Eq. 1 (JDC MK1 Porosimeter manual: www.jdc.ch/en/scientific-line/poros imetre-mk1). Antifungi tests on the samples were carried out using yeast and mould media prepared in petri dishes. Appropriate sized nanofiber mat pieces were measured and cut from each of the samples to be tested. The cut samples were sterilized and spread on the yeast and mould agar. The plates were then incubated at $25-28^{\circ} \mathrm{C}$ for 5 days. The plates were inspected and the average number of colonies per square centimetre were counted from the plates for each sample after 5 days. In order to evaluate the effectiveness of the mats as fruit and vegetable package materials, simple tests were carried out by covering strawberry fruits with neat and Ag-loaded nanofiber mats which were then kept in a dark environment at over $68 \%$ $\mathrm{RH}$ and $25-28{ }^{\circ} \mathrm{C}$ so as to accelerate mould colonisation and growth on the samples. Condition of the fruits was checked after 7 days and 12 days

Air permeability $=\frac{5400}{\text { time in secs. }}\left(\mathrm{L} / \mathrm{m}^{2} / \mathrm{min}\right)$.

\subsection{Factors investigated}

The effects of silver nanoparticles concentration on electrospun nanofiber mean diameter, nanofiber mat air permeability rates and against common fungi affecting fresh produce were the factors investigated in this study. Tensile strength of the nanofiber mats was determined for comparison against standard values of polymer packaging films. Correlations between Ag nanoparticles concentration and nanofiber mean diameters were determined using regression analysis. Analysis of variance (ANOVA) was used to determine the magnitude of variations between nanofiber diameters with change in Ag nanoparticle concentration.

\section{Results and discussion}

\subsection{Morphology}

The electrospun nanofiber diameter distributions are illustrated in Fig. 1.

The SEM images of the electrospun nanofiber mats are shown in Fig. 2.

The addition of Ag nanoparticles into electrospinning solutions has been reported not to have any effect on solution viscosity and surface tension but results in an increase in solution charge density. During electrospinning, the increased charge density subjects the jet to stronger stretching forces causing an overall reduction in fiber diameter with increasing Ag nanoparticles content, as have been reported by others [28, 52].

As observed in this study, there was reduction in the average diameter of both PVC and CA nanofibers with addition and increase of Ag nanoparticles as illustrated in Fig. 3. SEM images of electrospun neat CA indicated presence of few scattered elongated beads which were not seen after the addition of Ag nanoparticles. Fong et al. [53] explained that the increase in net charge density during electrospinning reduces the size and formation of beads i.e. beads on fibers become smaller and spindle-like and fiber diameter decreases with increase in charge density. The mechanism of bead formation during electrospinning has also been described [54]. The increased electric field force due to Ag nanoparticles content in CA solutions deformed any beads that could have been formed resulting in smooth and thinner fibers.

Reduction in diameter with increase in Ag nanoparticles content occurred in an almost linear manner having regression models with coefficients of determination $\left(R^{2}\right)$ of 0.956 and 0.972 for PVC and CA respectively. Analysis of variances at $a=0.05$ indicated significant reduction in nanofiber diameter with addition and gradual increment of Ag nanoparticles in the electrospinning solutions as shown in Tables 2 and 3.

\subsection{Tensile strength}

The mechanical properties of electrospun nanofiber mats are influenced by the degree of fiber orientation, fiber smoothness as well as the longitudinal and cross-sectional uniformity of individual nanofiber strands [50]. It is generally understood that the mechanical performance of materials of textile fabric nature depends on the microstructure and on the dominant deformation and fracture micro-mechanisms [55]. For self-bonded randomly aligned nanofiber mats, a one-dimensional tensile load application along the mat's plane causes the strands to rotate as they as they align in the direction of force and eventually break at adhesion points between fibers. The stress-strain curve as shown in Fig. 4 elaborates the breaking mechanism of randomly aligned nanofiber mats. Two zones exist on the curve: a high modulus zone indicating severing of adhesion points between fibers, and a lower modulus zone where fibers slide over each other before total failure.

Tensile characteristics of flexible packaging materials can be described as inferior ( $<1 \mathrm{MPa})$, marginal (1-10 MPa), good (10-100 MPa), or superior (>100 MPa) [5]. From the results of this study, the tensile characteristics of CA electrospun nanofiber mats could be described as marginal since they had an average strength of $8.6 \mathrm{MPa}$ while PVC nanofiber mats had an average strength of $13 \mathrm{MPa}$, and could be said to have good mechanical properties as a 

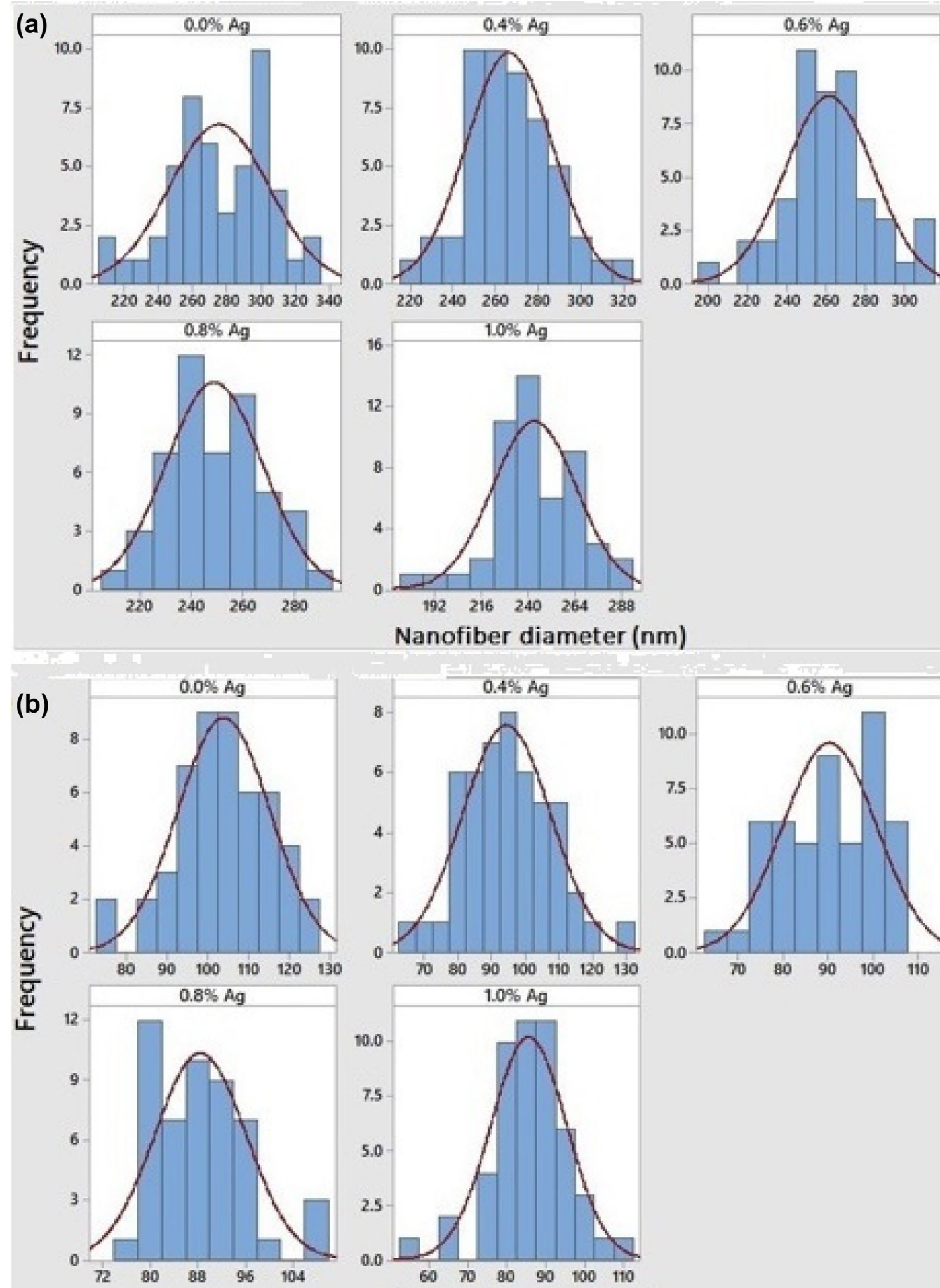

Nanofiber diameter (nm)
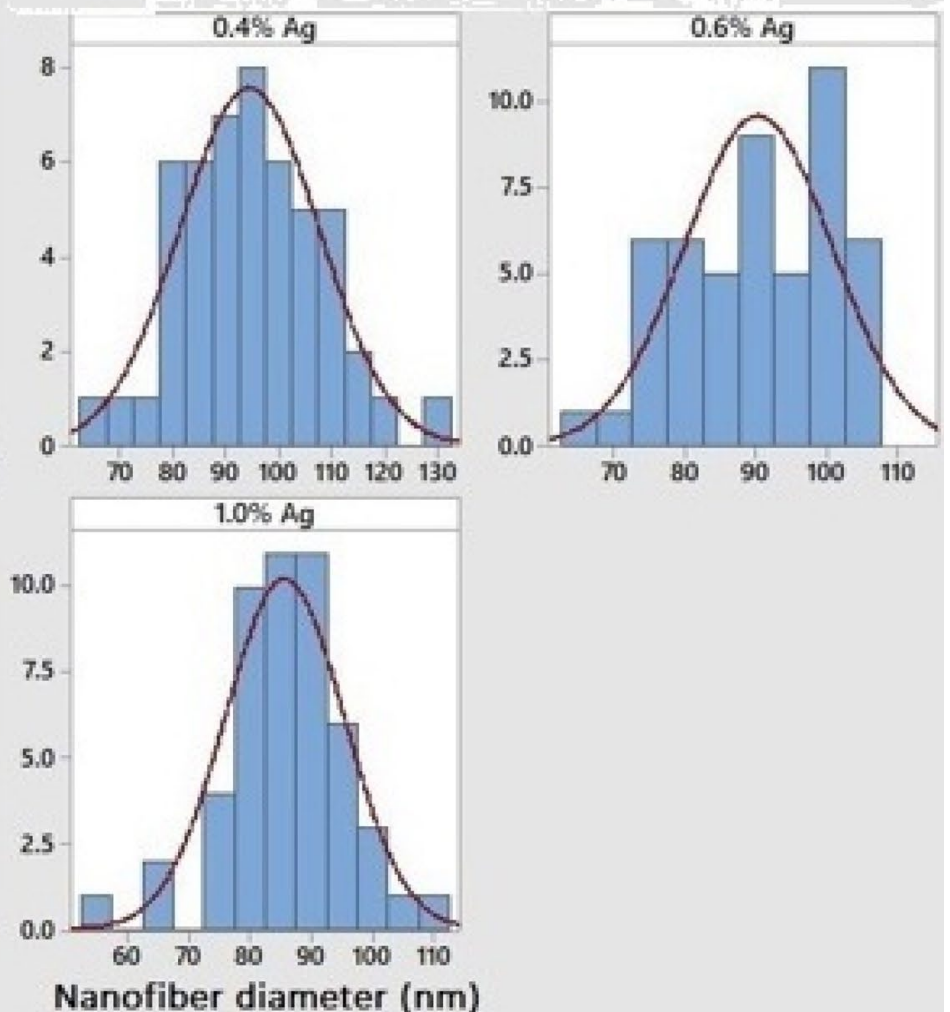

Fig. 1 a PVC, b CA nanofiber diameter distributions at different Ag nanoparticles concentrations 

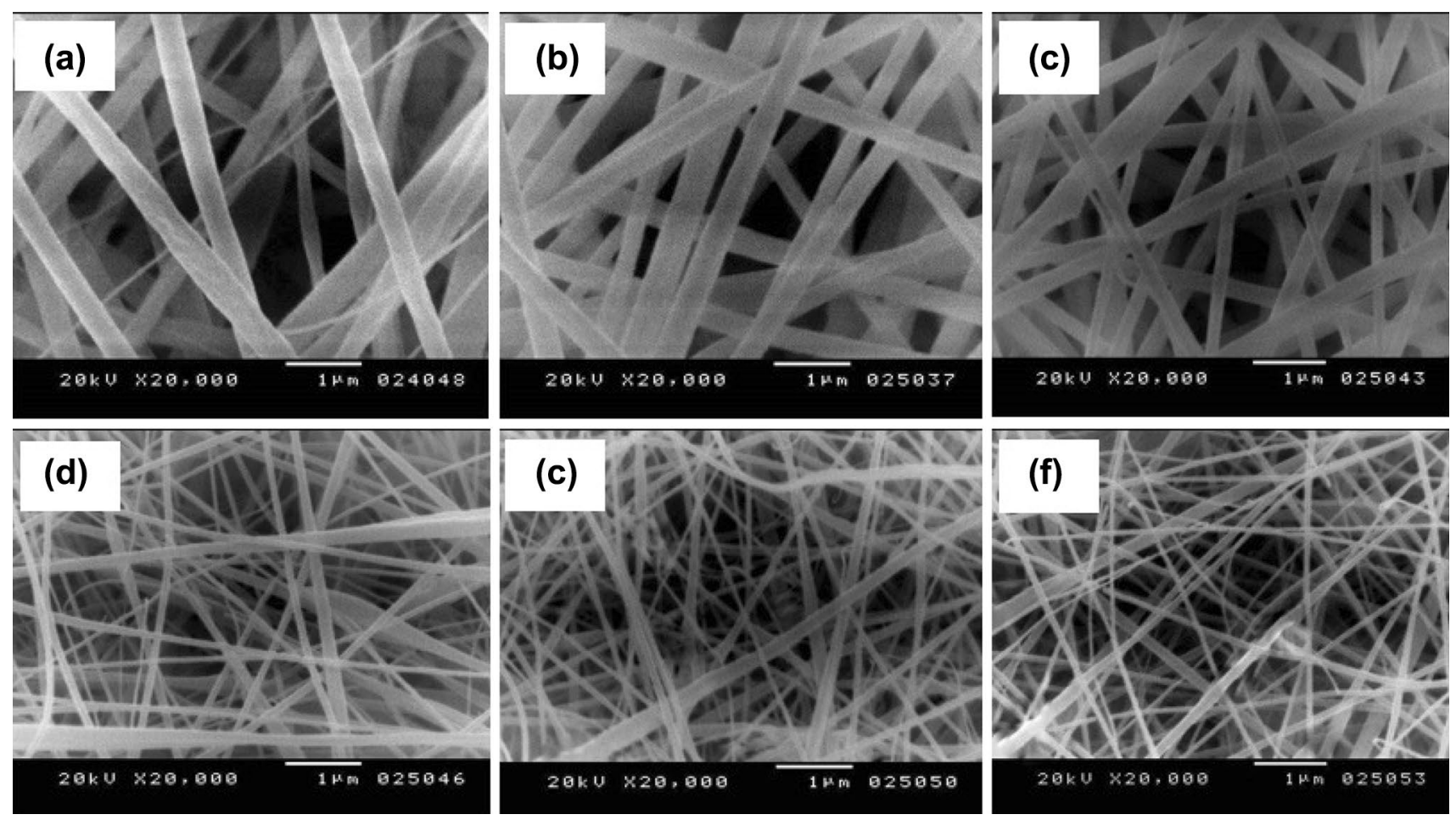

Fig. 2 SEM images of electrospun 16 wt\% PVC containing, a 0, b 0.6, c 1 wt \% Ag nanoparticles and 16 wt $\%$ CA containing, d 0, e 0.6, f 1 wt $\%$ Ag nanoparticles

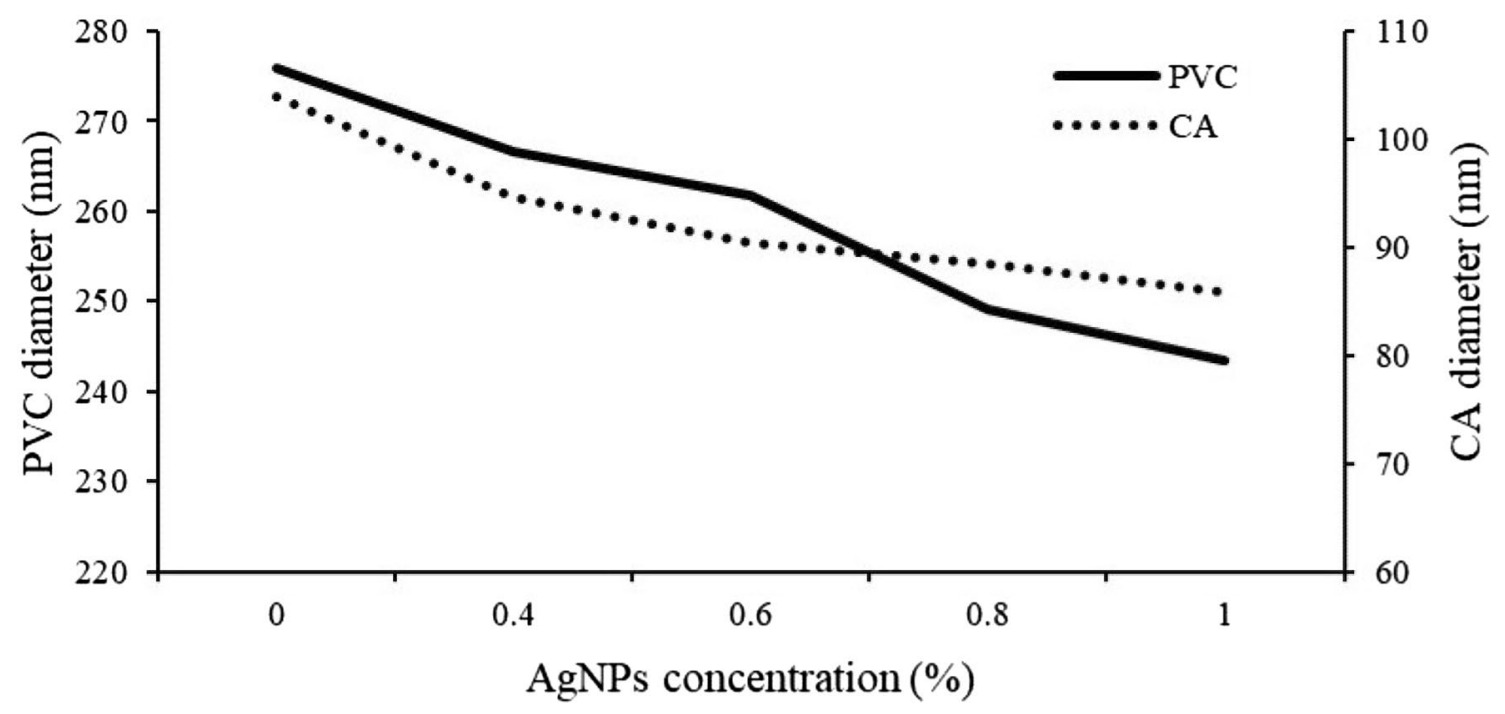

Fig. 3 Effect of Ag nanoparticles on nanofiber diameter

Table 2 ANOVA of CA nanofiber diameters with 0 , $0.4,0.6,0.8$ and $1 \mathrm{wt} \% \mathrm{Ag}$ nanoparticles

SN Applied Sciences

\begin{tabular}{llrllll}
\hline Source of variation & \multicolumn{1}{l}{ SS } & $d f$ & MS & F & $P$ value & $F$ crit \\
\hline Between groups & $10,281.55$ & 4 & 2570.388 & 23.18203 & $2.6 \mathrm{E}-16$ & 2.407751 \\
Within groups & $27,719.61$ & 250 & 110.8785 & & & \\
Total & $38,001.17$ & 254 & & & & \\
\hline
\end{tabular}


Table 3 ANOVA of PVC nanofiber diameters with 0 , $0.4,0.6,0.8$ and $1 \mathrm{wt} \% \mathrm{Ag}$ nanoparticles

\begin{tabular}{lcrrlll}
\hline Source of variation & \multicolumn{1}{l}{ SS } & $d f$ & MS & F & $P$ value & F crit \\
\hline Between groups & $35,389.29$ & 4 & 8847.323 & 17.27192 & $1.59 \mathrm{E}-12$ & 2.407751 \\
Within groups & $128,059.3$ & 250 & 512.2373 & & & \\
Total & $163,448.6$ & 254 & & & & \\
\hline
\end{tabular}

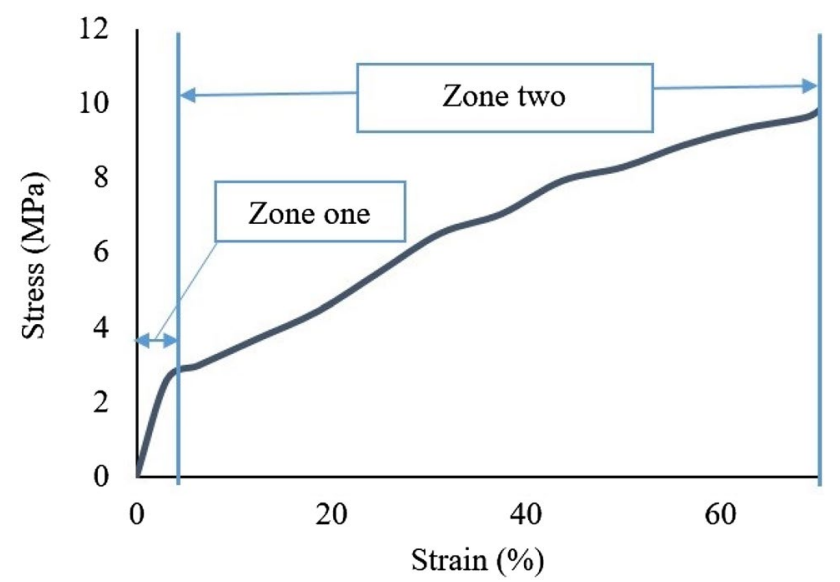

Fig. 4 Stress-strain curve of 16 wt\% PVC nanofiber mat showing the two zones of failure of randomly aligned nanofiber mats

packaging material. The average tensile strengths for $C A$ and PVC cast films were $22 \mathrm{MPa}$ and $42 \mathrm{MPa}$ respectively. Even though the electrospun nanofiber mats performed fairly with respect to tensile strength, it is expected that their overall strength would be inferior. This is because, in a packaging material, four aspects of strength must be considered: resistance to breaking when slowly pulled (tensile strength), resistance to breaking under sudden impact, resistance to puncturing by sharp objects and resistance to propagation of a tear resulting from puncturing [56]. Polymers used for manufacturing packaging materials have these properties occurring differently, and should also be different for different structures; films and nonwovens in this case. It is believed that a nanocomposite developed from a nanofiber mat and cast film would have good general mechanical properties sufficient for a packaging material.

\subsection{Air permeability}

Gas permeability of food packaging materials is an important factor as it determines the shelf-life and other characteristics (aroma, flavour etc.) of the packaged food. For long shelf-life food packaging materials, they should have as low permeability as possible to be able to preserve the valuable characteristics of the particular food product. Polymer based flexible packaging materials are permeable at varying degrees to small molecules of gases, moisture, organic vapour and to other low molecular weight compounds and additives that may be present in food [57]. Due to their porous nature, electrospun nanofiber mats exhibit higher permeability than polymeric films. The permeability rates are tuneable by manipulating the properties of nanofibers such as fiber diameter, membrane thickness, multi-layering etc. From the results of this study, the electrospun CA nanofiber mat exhibited significantly lower air permeability than the PVC nanofiber mat. This was attributed to the smaller diameters of CA nanofibers which resulted in higher fiber packing per unit volume of the membranes. Cast films had the lowest permeability for obvious reasons. Nonwoven mats with thinner fibers possess more fiber crossings within the membrane, hence have smaller pore sizes resulting in flow reduction. Furthermore, the higher specific surface area presented by thinner fibers, causes mats with such fibers to have high resistance to air flow. It is established that flow through a nanofiber mat is low when fiber diameter and pore sizes are small [58]. High fiber packing factors are achieved when small diameter fibers are used to fabricate a nonwoven membrane. For a given membrane, fiber packing factor is the ratio of membrane density to fiber density. Since the electrospun nanofiber mats comprise of randomly oriented self-bonded fibers, the relation in Eq. 2 [59] can be applied to determine the fiber packing factor. It is evident from the equation that the closer the volume of the fiber gets to the volume of the membrane, the packing factor approaches unity

Fiber packing factor (PF) $=\frac{\text { membrane density }}{\text { fiber density }}=\frac{W / V_{t}}{W / V_{f}}=\frac{V_{f}}{V_{t}}$

where $W$ membrane weight, $V_{t}$ total membrane volume and $V_{f}$ fiber volume.

In a study on the morphological properties of electrospun nanofibers, it was found that with increasing polymer concentration, the average pore size and nanofiber diameter increased implying that for minimum permeability of electrospun nanofiber membranes, the smallest possible fiber diameter is necessary [60]. The difference between the air permeability rates of electrospun CA and PVC nanofibers at $16 \mathrm{wt} \%$ concentration is illustrated in Fig. 5.

From this study, it can be said that CA nanofiber mats would perform better than the PVC nanofiber mats as materials for packaging with regards to gas or moisture 
Fig. 5 CA and PVC nanofiber mats air permeability rates

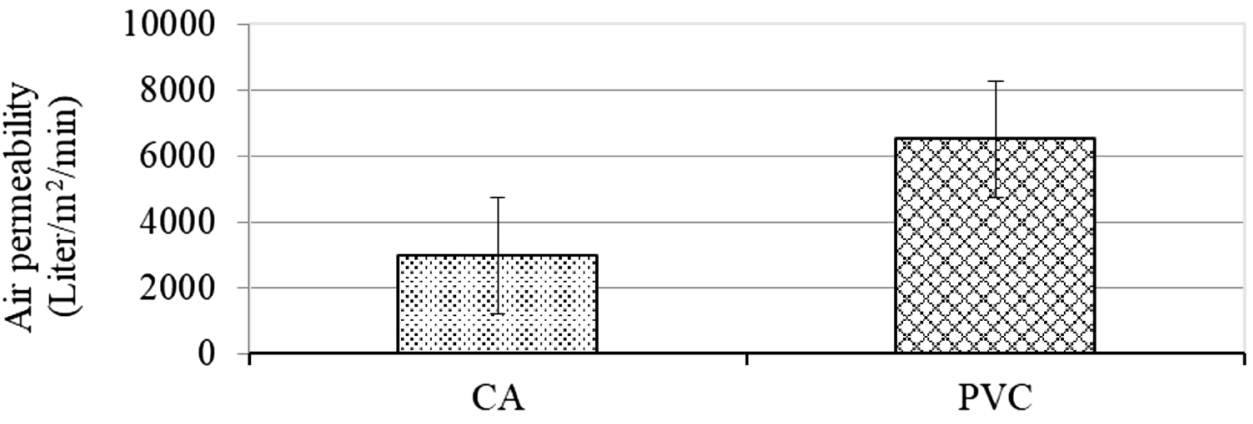

permeability. However, it is believed that a nanocomposite structure composed of layers of nanofiber mats and cast films could offer the lowest gas permeability rates as well as offer the ability of encapsulating an antimicrobial agent optimally. Preliminary findings have shown that gas permeability of a nanofiber-cast film nanocomposite film is significantly lower than that of a single layer cast film.

\subsection{Antifungi and simple mat-covered-fruit tests}

Simple mat-covered-fruit evaluation of the electrospun nanofiber mats was done using strawberry fruits whose conditions were checked after 7 and 12 days as illustrated in Fig. 6.

From the simple mat-covered-fruit test, it was seen that mould formed on the surfaces of the covered strawberry fruits to varying extents. As well, the conditions of storage contributed to rapid physical damage to the fruits and caused them to stick to the nanofiber mats. The fruit covered by $1 \%$ Ag-loaded PVC nanofiber mat exhibited the lowest observable mould growth at the 7 th and 12th day checking. As shown in Fig. 6, physical spoilage of the fruit was evident but little mould growth was seen on the surface. The fruit covered with $1 \% \mathrm{Ag}$-loaded CA nanofiber mat also showed low mould growth at the 7th day checking, but there was increased mould development by the 12 th day. Fruits covered by neat CA and PVC nanofiber mats showed the highest development of mould at the 7th and 12th day checking with the mould completely enveloping the fruits by the 12th day. From the packaging tests, it can be concluded that the presence of Ag nanoparticles on the Ag-loaded nanofiber mats contributed to the lower development of mould on their fruit surfaces as compared to the neat CA and PVC covered fruits.

Antifungi properties of the Ag loaded and neat nanofiber mat and films were evaluated from the 5-day incubated yeast and mould agar plates. It was observed that both PVC and CA nanofiber mats loaded with Ag nanoparticles exhibited inhibited growth of the yeast and mould after the incubation period when compared to the neat nanofiber mats and cast films as illustrated in Fig. 7. As expected, the presence of the Ag nanoparticles in the nanofiber mats provided a non-conducive environment for the microorganisms to thrive thus augmenting the postulation that nanoparticles of silver have capability to inhibit growth of multiple bacteria as well as fungi. Effective antimicrobial activity of Ag nanoparticles loaded on CA, PVC and PVA nanofibers has been demonstrated previously against gram negative bacteria [61]. Son et al. [28] reported on the effectiveness of Ag nanoparticles loaded on CA nanofibers against both gram negative and gram positive bacteria. Quirós et al. [37] reported that the growth of fungi was considerably weakened when spores were incubated in direct contact with Ag nanoparticles or on cellulose acetate composite membranes containing the nanoparticles. In this study, the antifungal activity of Ag nanoparticles loaded on electrospun PVC and CA nanofibers is shown where there is significant yeast and mould growth inhibition on the surfaces of the materials containing Ag nanoparticles.

As shown in Fig. 7, it was observed that PVC cast films had high formation of the microorganism colonies compared to the nanofiber mats. This was attributed to the different morphological features of the materials. It has been reported that the initial stages of growth of fungi are highly influenced by the features of the substrate [32]. Quirós et al. [37] thought that lower growth of fungi on electrospun CA composites containing $\mathrm{Ag}$ and $\mathrm{Cu}$ nanoparticles supported in sepiolite and mesoporous silica was contributed to by the interference of fibers with the growing mycelium. Wösten et al. [62] also observed that the hyphae of a growing fungus in a thin agarose layer could not grow through perforated polycarbornate membranes and prevented spore formation. In this study, it is believed that the PVC nanofibers interfered with growth of fungi, hence reducing the number of colonies formed on the nanofiber mats compared to the cast film. For CA, however, the neat nanofiber mats exhibited a higher count of colonies than in the cast film and the neat PVC nanofiber mats. This was attributed to the difference in nanofiber mat densities and surface properties whereby CA nanofiber mats had a denser structure due to thinner fibers and some spindle shaped elongated beads. Also, the low strength of raised surface fibers may have resulted in 


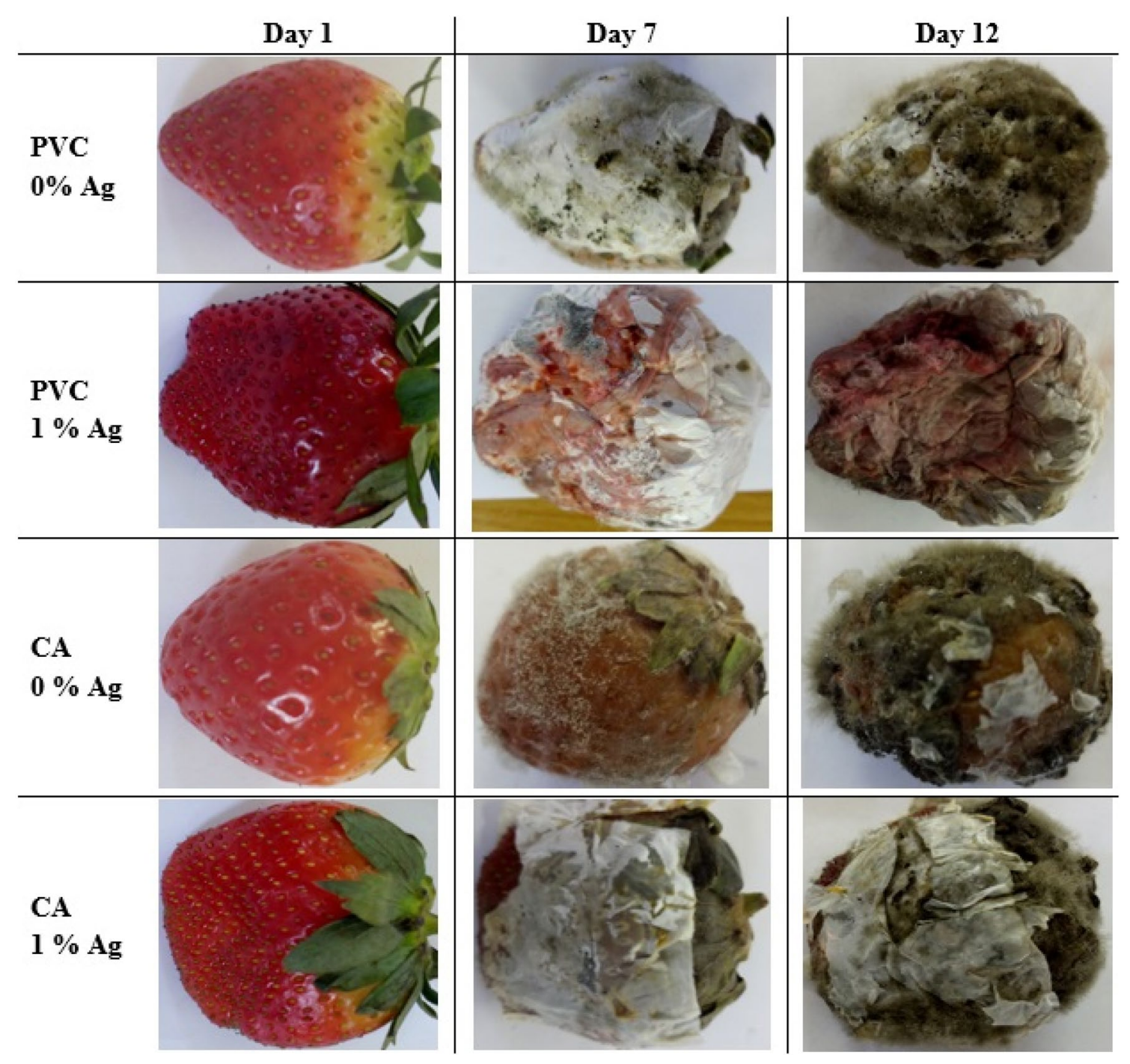

Fig. 6 Strawberry fruit appearance; not covered at day 1, and after covering with neat and Ag-loaded CA and PVC nanofiber mats for up to 12 days at mould growth favouring conditions

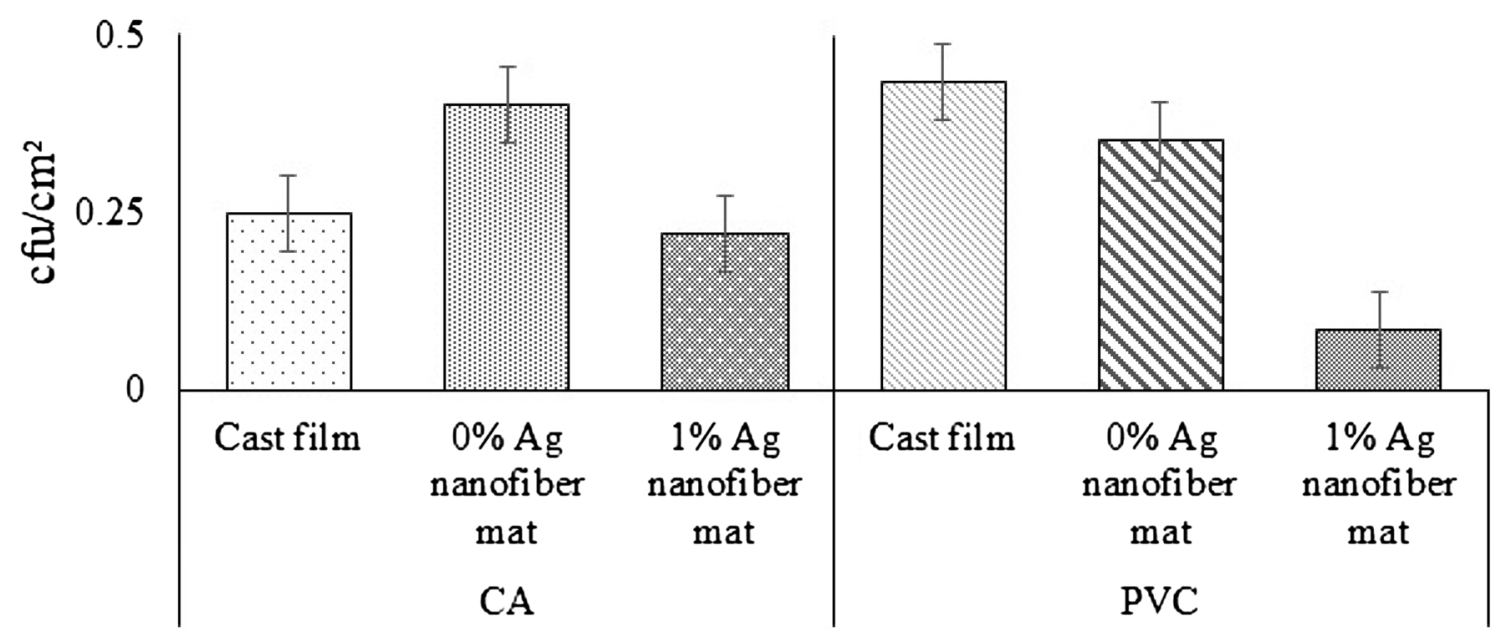

Fig. 7 Yeast and mould growth on the cast films and nanofiber mats with and without Ag nanoparticles 
broken and raised ends at the surface during handling. It is believed that surface beads and raised broken nanofiber ends provided convenient support locations for the microbes to colonise and grow from and that the CA mats high density fiber network interfered with their growth into the structure, causing them to grow outwards thus accelerated growth. For the other polymer, it is thought that the more hydrophobic environment presented by the neat PVC film and mats allowed for rapid reproduction of the yeast and mould colonies [63], hence their higher yeast and mould colony count especially on the film. Jiang et al. [64] reported that some fungi have increased activity as hydrophobicity is increased. Figure 8 shows SEM of CA nanofiber mat with broken fiber ends encircled.

As regards the mode of action of Ag nanoparticles against microbes, there is no general agreement, especially against fungi, but there have been attributions to interference with vital cellular processes, disruption of DNA replication and oxidative stress through the catalysis of ROS formation induced by both direct contact with nanoparticles and the presence of silver ions [65-67]. It has been suggested that when the nanoparticles come in contact with a microorganism, they get anchored to the cell wall and eventually penetrate it resulting in changes on the cell surface and membrane structure [68]. Lala et al. [61] explained that the cation $\mathrm{Ag}^{+}$binds to the cell bringing about structural and functional damages at multiple sites consequently destroying the cell wall and eventual death of the organism. From an antimicrobial study of silver against some fungi, it was reported that Ag nanoparticles are able to bind to a yeast cell wall and membrane resulting in the effluence of the cells' contents [69]. Another theory of action is that the Ag nanoparticles

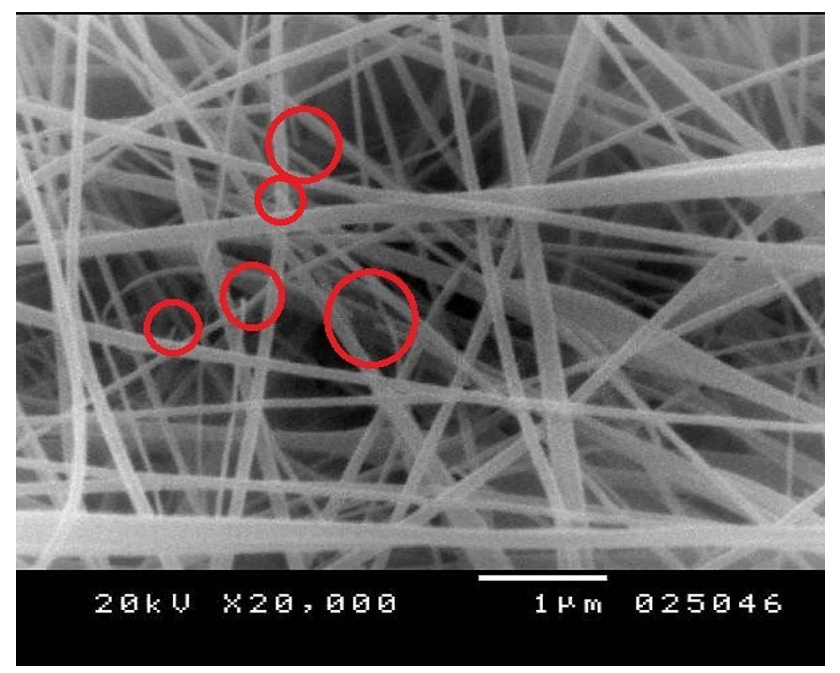

Fig. 8 SEM CA nanofiber mat showing broken fiber ends (encircled) at the surface release ions which interact with the microbes enzymes causing inhibition of vital cellular functions [70]. It has been suggested that the fungicidal activity of Ag nanoparticles could be by disruption of the cell membrane structure, distorting the cell's potential gradient, thereby inhibiting the normal budding process and mycelia growth [67, 71]. Some recent studies reported that Ag nanoparticles can change the metabolism of moulds and also alter the microorganism's ultrastructure through cell ultrastructural reorganisation, shortening and condensation of hyphae, cell plasmolysis, increased vacuolisation, multiple membranous structures, collapsed cytoplasm, accumulation of lipid material, condensed mitochondria, disintegration of organelles, nuclear deformation, condensation and fragmentation of chromatin, creation of apoptotic bodies and a new inside cell wall $[72,73]$. Prabhu and Poulose [74] have also described some of the antimicrobial actions of Ag nanoparticles. It is worthy to note, however, that the antifungal activity of Ag nanoparticles is lower than their antibacterial activity [75].

\section{Conclusion}

CA and PVC nanofiber mats containing Ag nanoparticles fabricated through electrospinning were evaluated for their potential use as antifungal food packaging materials. The nanofiber mats were characterized by SEM, air permeability and tensile strength tests. A reduction in fiber diameter was observed with the addition of Ag nanoparticles into the electrospinning solution for both polymers. This was attributed to the increase in the net charge density and electric field force during electrospinning. CA had thinner nanofibers than PVC at the same $w / w$ solution concentration primarily due to the higher molecular weight of the PVC used. The stress-strain curves of the nanofiber mats showed two regions with differing mechanical behaviours (a high modulus region and a low modulus region) implying different forces of different magnitudes holding the nonwoven based material together. It was found that the nanofiber mats had marginal to good tensile strength values relative to film based packaging materials. On antimicrobial action, neat electrospun PVC mats had significantly lower microbes' growth compared to neat PVC films which might have been due to interference of the growing mycelium by the nanofibers thus delaying rapid multiplication of the colonies. On the other hand, neat CA nanofiber mat higher density, elongated surface beads and possible raised broken ends could have contributed to the high colony count on the nanofiber mat than on the film. The antifungal activity of Ag nanoparticles is evident as observed in nanofiber mats of both polymers whereby there was inhibited growth of yeast and mould 
on the mat surfaces after inclusion of the agent. This indicates promising success in the use of nanofibers for antifungi packaging of food products, especially for fresh fruits and vegetables.

\section{Compliance with ethical standards}

Conflict of interest The authors declare that they have no conflict of interest.

\section{References}

1. Robertson GL (2012) Food packaging: principles and practice. CRC Press, Boca Raton

2. Zagory D, Kader AA (1988) Modified atmosphere packaging of fresh produce. Food Technol 42(9):70-77

3. Biji K, Ravishankar C, Mohan C, Gopal TS (2015) Smart packaging systems for food applications: a review. J Food Sci Technol 52:1-11

4. Realini CE, Marcos B (2014) Active and intelligent packaging systems for a modern society. Meat Sci 98(3):404-419

5. Han JH (2005) Innovations in food packaging. Academic, Berlin

6. Rodrigues ET, Han JH (2003) Intelligent packaging. In: Heldman DR (ed) Encyclopedia of agricultural, food, and biological engineering, 1st edn. Marcel Dekker, Inc., New York, pp 528-535

7. Emamifar A (2011) Applications of antimicrobial polymer nanocomposites in food packaging. INTECH Open Access Publisher, New York

8. Torres-Giner S (2011) Electrospun nanofibers for food packaging applications. In: Lagarón J-M (ed) Multifunctional and nanoreinforced polymers for food packaging. Woodhead Publishing, pp 108-125

9. Moreira JB, de Morais MG, de Morais EG, da Silva Vaz B, Costa JAV (2018) Electrospun polymeric nanofibers in food packaging. In: Grumezescu AM, Holban AM (eds) Impact of nanoscience in the food industry. Elsevier, pp 387-417

10. Doyle JJ, Choudhari S, Ramakrishna S, Babu RP (2013) Electrospun nanomaterials: biotechnology, food, water, environment, and energy. In: Conference papers in science. Hindawi Publishing Corporation

11. Pillay V, Dott C, Choonara YE, Tyagi C, Tomar L, Kumar P, du Toit LC, Ndesendo VM (2013) A review of the effect of processing variables on the fabrication of electrospun nanofibers for drug delivery applications. J Nanomater 2013:22

12. Jiang S, Hou H, Agarwal S, Greiner A (2016) Polyimide nanofibers by "Green" electrospinning via aqueous solution for filtration applications. ACS Sustain Chem Eng 4(9):4797-4804

13. Matulevicius J, Kliucininkas L, Prasauskas T, Buivydiene D, Martuzevicius D (2016) The comparative study of aerosol filtration by electrospun polyamide, polyvinyl acetate, polyacrylonitrile and cellulose acetate nanofiber media. J Aerosol Sci 92:27-37

14. Hasan A, Memic A, Annabi N, Hossain M, Paul A, Dokmeci MR, Dehghani F, Khademhosseini A (2014) Electrospun scaffolds for tissue engineering of vascular grafts. Acta Biomater 10(1):11-25

15. Hudecki A, Gola J, Ghavami S, Skonieczna M, Markowski J, Likus W, Lewandowska M, Maziarz W, Los MJ (2017) Structure and properties of slow-resorbing nanofibers obtained by (co-axial) electrospinning as tissue scaffolds in regenerative medicine. PeerJ 5:e4125

16. Yang $X$, Fan L, Ma L, Wang Y, Lin S, Yu F, Pan X, Luo G, Zhang D, Wang H (2017) Green electrospun Manuka honey/silk fibroin fibrous matrices as potential wound dressing. Mater Des 119:76-84

17. Hassiba AJ, El Zowalaty ME, Webster TJ, Abdullah AM, Nasrallah GK, Khalil KA, Luyt AS, Elzatahry AA (2017) Synthesis, characterization, and antimicrobial properties of novel double layer nanocomposite electrospun fibers for wound dressing applications. Int J Nanomed 12:2205

18. Mouriño V (2018) Nanoelectrospun matrices for localized drug delivery. In: Inamuddin, Asiri AM, Ali M (eds) Applications of nanocomposite materials in drug delivery. Elsevier, Amsterdam, pp 491-508

19. Akhgari A, Heshmati Z, Garekani HA, Sadeghi F, Sabbagh A, Makhmalzadeh BS, Nokhodchi A (2017) Indomethacin electrospun nanofibers for colonic drug delivery: in vitro dissolution studies. Colloids Surf B 152:29-35

20. Lee KH, Ki CS, Baek DH, Kang GD, Ihm D-W, Park YH (2005) Application of electrospun silk fibroin nanofibers as an immobilization support of enzyme. Fibers Polym 6(3):181-185

21. Peng S, Li L, Hu Y, Srinivasan M, Cheng F, Chen J, Ramakrishna S (2015) Fabrication of spinel one-dimensional architectures by single-spinneret electrospinning for energy storage applications. ACS Nano 9(2):1945-1954

22. Dai Y, Liu W, Formo E, Sun Y, Xia Y (2011) Ceramic nanofibers fabricated by electrospinning and their applications in catalysis, environmental science, and energy technology. Polym Adv Technol 22(3):326-338

23. Van Hoang N, Hung CM, Hoa ND, Van Duy N, Van Hieu N (2018) Facile on-chip electrospinning of $\mathrm{ZnFe}_{2} \mathrm{O}_{4}$ nanofiber sensors with excellent sensing performance to $\mathrm{H}_{2} \mathrm{~S}$ down ppb level. J Hazard Mater 360:6-16

24. Ma L, Ma S, Kang $H$, Shen $X$, Wang T, Jiang X, Chen $Q$ (2017) Preparation of $\mathrm{Ag}$-doped $\mathrm{ZnO}-\mathrm{SnO}_{2}$, hollow nanofibers with an enhanced ethanol sensing performance by electrospinning. Mater Lett 209:188-192

25. Dzenis Y, Cheng SZ, Harris F (2015) Advanced single-polymer nanofiber-reinforced composite-towards next generation ultralight superstrong/tough structural material. DTIC document

26. Teo W-E, Inai R, Ramakrishna S (2011) Technological advances in electrospinning of nanofibers. Sci Technol Adv Mater 12(1):013002

27. Kayaci F, Uyar T (2012) Encapsulation of vanillin/cyclodextrin inclusion complex in electrospun polyvinyl alcohol (PVA) nanowebs: prolonged shelf-life and high temperature stability of vanillin. Food Chem 133(3):641-649

28. Son WK, Youk JH, Lee TS, Park WH (2004) Preparation of antimicrobial ultrafine cellulose acetate fibers with silver nanoparticles. Macromol Rapid Commun 25(18):1632-1637

29. Amna T, Yang J, Ryu K-S, Hwang I (2015) Electrospun antimicrobial hybrid mats: innovative packaging material for meat and meat-products. J Food Sci Technol 52(7):4600-4606

30. Teo W-E (2015) Electrospun fibers for fungus control. http://elect rospintech.com/funguscontrol.html

31. Tournas V, Stack M, Mislivec P, Koch H, Bandler R (1998) Yeasts, molds and mycotoxins. Association of official analytical chemists-AOAC Bacteriological analytical manual 8th ed Gaithersburg: $A O A C: 1-11$

32. Krijgsheld P, Bleichrodt R, Van Veluw G, Wang F, Müller W, Dijksterhuis J, Wösten H (2013) Development in Aspergillus. Stud Mycol 74:1-29

33. Brody AL, Strupinsky E, Kline LR (2001) Active packaging for food applications. CRC Press, Boca Raton

34. Brody A, Budny J (1995) Enzymes as active packaging agents. In: Rooney ML (ed) Active food packaging. Springer, pp 174-192

35. Duncan TV (2011) Applications of nanotechnology in food packaging and food safety: barrier materials, antimicrobials and sensors. J Colloid Interface Sci 363(1):1-24 
36. Son WK, Youk JH, Park WH (2006) Antimicrobial cellulose acetate nanofibers containing silver nanoparticles. Carbohyd Polym 65(4):430-434

37. Quirós J, Gonzalo S, Jalvo B, Boltes K, Perdigón-Melón JA, Rosal R (2016) Electrospun cellulose acetate composites containing supported metal nanoparticles for antifungal membranes. Sci Total Environ 563:912-920

38. Fernandez A, Picouet P, Lloret E (2010) Reduction of the spoilage-related microflora in absorbent pads by silver nanotechnology during modified atmosphere packaging of beef meat. J Food Prot 73(12):2263-2269

39. Fernández A, Picouet $P$, Lloret E (2010) Cellulose-silver nanoparticle hybrid materials to control spoilage-related microflora in absorbent pads located in trays of fresh-cut melon. Int J Food Microbiol 142(1):222-228

40. Danza A, Conte A, Mastromatteo M, Nobile M (2015) A new example of nanotechnology applied to minimally processed fruit: the case of fresh-cut melon. J Food Process Technol 6(439):2

41. Titow WV (2012) PVC plastics: properties, processing, and applications. Springer, Berlin

42. Fischer I, Schmitt WF, Porth HC, Allsopp MW, Vianello G (2014) Poly(vinyl chloride). Ullmann's Encyclopedia of Industrial Chemistry, New York

43. Twede D (2010) Economics of packaging. In: Yam KL (ed) The Wiley encyclopedia of packaging technology, 3rd edn. Wiley, USA, pp 383-389. https://doi.org/10.1002/9780470541395

44. Es-Saheb M, Elzatahry AA, Sherif E, Alkaraki AS, Kenawy E-R (2012) A novel electrospinning application for polyvinyl chloride nanofiber coating deposition as a corrosion inhibitor for aluminum, steel, and brass in chloride solutions. Int J Electrochem Sci 7(7):5962-5976

45. Lee KH, Kim HY, La YM, Lee DR, Sung NH (2002) Influence of a mixing solvent with tetrahydrofuran and $N, N$-dimethylformamide on electrospun poly(vinyl chloride) nonwoven mats. J Polym Sci Part B: Polym Phys 40(19):2259-2268

46. Jin $\mathrm{T}$, Zhang $\mathrm{H}$ (2008) Biodegradable polylactic acid polymer with nisin for use in antimicrobial food packaging. J Food Sci 73(3):M127-M134

47. Leceta I, Guerrero P, Ibarburu I, Dueñas M, De la Caba K (2013) Characterization and antimicrobial analysis of chitosan-based films. J Food Eng 116(4):889-899

48. Dutta P, Tripathi S, Mehrotra G, Dutta J (2009) Perspectives for chitosan based antimicrobial films in food applications. Food Chem 114(4):1173-1182

49. Kim HG, Kim JH (2011) Preparation and properties of antibacterial Poly(vinyl alcohol) nanofibers by nanoparticles. Fibers Polym 12(5):602-609

50. Tarus B, Fadel N, Al-Oufy A, El-Messiry M (2016) Effect of polymer concentration on the morphology and mechanical characteristics of electrospun cellulose acetate and poly(vinyl chloride) nanofiber mats. Alex Eng J 55(3):2975-2984

51. Tungprapa S, Puangparn T, Weerasombut $M$, Jangchud I, Fakum P, Semongkhol S, Meechaisue C, Supaphol P (2007) Electrospun cellulose acetate fibers: effect of solvent system on morphology and fiber diameter. Cellulose 14(6):563-575

52. An J, Zhang H, Zhang J, Zhao Y, Yuan X (2009) Preparation and antibacterial activity of electrospun chitosan/poly(ethylene oxide) membranes containing silver nanoparticles. Colloid Polym Sci 287(12):1425-1434

53. Fong H, Chun I, Reneker D (1999) Beaded nanofibers formed during electrospinning. Polymer 40(16):4585-4592

54. Zhu S, Yu H, Chen Y, Zhu M (2012) Study on the morphologies and formational mechanism of poly(hydroxybutyrate-cohydroxyvalerate) ultrafine fibers by dry-jet-wet-electrospinning. J Nanomater 2012:16
55. Ridruejo A, González C, LLorca J (2011) Micromechanisms of deformation and fracture of polypropylene nonwoven fabrics. Int J Solids Struct 48(1):153-162

56. Jenkins WA, Osborn KR (1992) Plastic films: technology and packaging applications. CRC Press, Boca Raton

57. Siracusa V (2012) Food packaging permeability behaviour: a report. Int J Polym Sci 2012:11

58. Qin XH, Wang SY (2006) Filtration properties of electrospinning nanofibers. J Appl Polym Sci 102(2):1285-1290

59. Adanur S (2017) Wellington sears handbook of industrial textiles. Routledge, London

60. Širc J, Hobzová R, Kostina N, Munzarová M, Juklícková M, Lhotka M, Kubinová Š, Zajícová A, Michálek J (2012) Morphological characterization of nanofibers: methods and application in practice. J Nanomater 2012:121

61. Lala NL, Ramaseshan R, Bojun L, Sundarrajan S, Barhate R, Yingjun L, Ramakrishna S (2007) Fabrication of nanofibers with antimicrobial functionality used as filters: protection against bacterial contaminants. Biotechnol Bioeng 97(6):1357-1365

62. Wösten HA, Moukha SM, Sietsma JH, Wessels JG (1991) Localization of growth and secretion of proteins in Aspergillus niger. Microbiology 137(8):2017-2023

63. Wösten HA (2001) Hydrophobins: multipurpose proteins. Ann Rev Microbiol 55(1):625-646

64. Jiang Z, Kullberg BJ, Van Der Lee H, Vasil Al, Hale JD, Mant CT, Hancock RE, Vasil ML, Netea MG, Hodges RS (2008) Effects of hydrophobicity on the antifungal activity of a-helical antimicrobial peptides. Chem Biol Drug Des 72(6):483-495

65. Luoma SN (2008) Silver nanotechnologies and the environment. The project on emerging nanotechnologies report 15

66. Rizzello L, Pompa PP (2014) Nanosilver-based antibacterial drugs and devices: mechanisms, methodological drawbacks, and guidelines. Chem Soc Rev 43(5):1501-1518

67. Lee J, Kim K-J, Sung WS, Kim JG, Lee DG (2010) The silver nanoparticle (Nano-Ag): a new model for antifungal agents. In: Pozo DP (ed) Silver nanoparticles. InTech, pp 295-308

68. Sondi I, Salopek-Sondi B (2004) Silver nanoparticles as antimicrobial agent: a case study on E. coli as a model for gram-negative bacteria. J Colloid Interface Sci 275(1):177-182

69. Nasrollahi A, Pourshamsian K, Mansourkiaee P (2011) Antifungal activity of silver nanoparticles on some of fungi. Int J Nano Dimens 1(3):233-239

70. Feng QL, Wu J, Chen G, Cui F, Kim T, Kim J (2000) A mechanistic study of the antibacterial effect of silver ions on Escherichia coli and Staphylococcus aureus. J Biomed Mater Res 52(4):662-668

71. Kim K-J, Sung WS, Suh BK, Moon S-K, Choi J-S, Kim JG, Lee DG (2009) Antifungal activity and mode of action of silver nanoparticles on Candida albicans. Biometals 22(2):235-242

72. Pietrzak K, Twarużek M, Czyżowska A, Kosicki R, Gutarowska B (2015) Influence of silver nanoparticles on metabolism and toxicity of moulds. Acta Biochim Polon 62(4):851-857

73. Pietrzak K, Glińska S, Gapińska M, Ruman T, Nowak A, Aydin E, Gutarowska B (2016) Silver nanoparticles: a mechanism of action on moulds. Metallomics 8(12):1294-1302

74. Prabhu S, Poulose EK (2012) Silver nanoparticles: mechanism of antimicrobial action, synthesis, medical applications, and toxicity effects. Int Nano Lett 2(1):32

75. Panáček $A$, Kolář $M$, Večeřová $R$, Prucek $R$, Soukupová J, Kryštof $V$, Hamal P, Zbořil R, Kvítek L (2009) Antifungal activity of silver nanoparticles against Candida spp. Biomaterials 30(31):6333-6340

Publisher's Note Springer Nature remains neutral with regard to jurisdictional claims in published maps and institutional affiliations. 